$\checkmark$ Research Square

\title{
Production of Biodiesel From Cashew Nut Shell Liquid Using Cashew Nut Shell Derived Bio-char Catalyst
}

Vanisree Geetha Sivan ( $\sim$ vaniisreegs@gmail.com )

NITC: National Institute of Technology Calicut https://orcid.org/0000-0002-3934-5917

Ansuya Paleri

NITC: National Institute of Technology Calicut

Aparna Kallingal

NITC: National Institute of Technology Calicut

\section{Research Article}

Keywords: Biochar, Biodiesel, FAME, CNSL, Transesterification

Posted Date: February 3rd, 2022

DOl: https://doi.org/10.21203/rs.3.rs-1253077/v1

License: (c) (i) This work is licensed under a Creative Commons Attribution 4.0 International License.

Read Full License 


\section{Abstract}

Biodiesel has recently received widespread attention as an essential source of renewable and environmentally friendly energy due to its ease of production and clean burning. Cashew nutshell is a biomass waste readily available in India. This work studies the production of fatty acid methyl ester (FAME) from the cashew nut shell liquid (CNSL) using sulfonated cashew nutshell biochar catalyst by transesterification reaction. Catalyst efficiency is compared with a conventional catalyst for biodiesel production. Characterization of the catalyst was done using FTIR, TGA, elemental analysis, and BET. Transesterification studies were carried out using $\mathrm{KOH}$ and the biochar catalyst. These studies inferred that the highest conversion of CNSL to FAME is achieved by using the conventional catalyst $\mathrm{KOH}(94.2 \%$ yield) and process parameters of $65^{\circ} \mathrm{C}$ reaction temperature, $1 \mathrm{hr}$ reaction time, $18: 1$ methanol to oil ratio, and $5 \mathrm{w} / \mathrm{w} \%$ catalyst weight. The highest conversion achieved using the biochar catalyst was $43.4 \%$ at optimum process parameters. The study revealed the feasibility of producing FAME from waste biomass, which lowers production costs and benefits environmental sustainability.

\section{Introduction}

The world's population is increasing, and the developing world's economies are expanding. Demand for fuel is always on the rise(Guo 2013). The major problem of fossil fuels is higher carbon emission and depletion of oil reserves(Ishola et al. 2020). The primary drivers of alternative fuels are sustainable development and environmental preservation(Justin Abraham Baby et al., 2021). Because of its superior performance and benefits of renewable, clean, degradable,pollution-free, non-toxic, biodiesel is often regarded as the most viable alternative energy source to petroleum diesel(Gohain et al. 2017; Zhang et al. 2020). Fatty acid methyl ester is another name of biodiesel. It can be made by transestrifying renewable sources such as vegetable oil, animal fats with short-chain alcohol in the presence of a catalyst.(Bastos et al. 2020; Guo et al. 2020).

Two different catalysts used to synthesize biodiesel are homogeneous and heterogeneous catalysts. homogeneous catalysts like sulphuric acid, sodium, and potassium hydroxides are highly active. However, their industrial applications are limited due to the side reaction of saponification, equipment corrosion, and separation complexity (Qu et al. 2020). heterogeneous catalysts have attracted widespread attention due to their advantages. non-toxic to the equipment(Chen et al. 2020), easily separable from the biodiesel product, which improves biodiesel quality and reduces post-treatment cost(Naik and Meivelu 2020). heterogeneous base catalyst is more efficient than heterogeneous acid catalyst as they catalyze the reaction $\mathbf{4 0 0 0}$ times faster than heterogeneous acid catalyst (Sahani et al. 2020). the major drawback of heterogeneous catalysts is that it requires high temperature and pressure for acidic heterogeneous catalysts, low acid value feedstock for basic catalysts, and high cost for immobilized enzymatic catalysts(Khandan and Saffarzadeh-Matin 2020).

The main drawback of using edible oils as biodiesel feedstock is their high cost, dependence on food price(Pikula et al. 2020).in the present study, cashew nut seed shell is used for the production of 
biodiesel. India is the second-largest producer, processor, and exporter of cashews in the world(Deepanraj et al., 2021). Cashew cultivation now covers a total area of 0.70 million hectares of land, producing over. 0.40 million M.T. of raw cashew nuts annually(Padmanaban et al. 2014). The cashew nut is separated from the fruit, washed, sun-dried, and roasted to extract the cashew nut and separate the cashew kernel. The nut has a shell of about 1/8th inch thickness inside, which is a soft honeycomb structure. The extractable oil is called cashew nut shell liquid and has numerous applications in the polymer industry such as friction lining, paints, and varnishes, rubber compounding resins, cashew cement, biocomposite, the monomer for polymers, etc. (Lubi and Thachil 2000; Smith Jr et al. 2003; Subbarao et al. 2011). Cashew Nut Shell Liquid (CNSL) is a useful cashew industry byproduct. The cashew nutshell contains $20 \%$ CNSL. The oil can be extracted by roasting the cashew kernel or by using an oil extraction method such as solvent extraction. Untreated CNSL is a dark reddish-brown liquid that is viscous and vesicant. Despite the fact that CNSL has a wide range of applications in the polymer area,(Taiwo 2015), few studies have been conducted on the feasibility of the oil as a feedstock for biodiesel preparation. Here focus is two fold, using cashewnut shell biomass which is an agriculture waste as an easily available biochar and using CSNL which is a cheap, non edible natural oil as a biodiesel source. Thus the entire cost of production can be significantly reduced.

\section{Experimental \\ 2.1.Materials}

Cashew nutshell biomass was collected from a Shelling plant in Tamil Nadu. Cashew nut shell liquid (CNSL) was extracted from the cashew nutshell using the solvent extraction method. Chemicals used for the extraction and catalyst preparation are Sodium hydroxide (Emplura Merck Specialties Private Ltd.), oxalic acid(spectram reagent \& Chemicals Pvt Ltd.), hydrochloric acid (Himedia Laboratories Private Ltd.), Phenolphthalein(Nice Chemicals Private Ltd.), Hexane(Sisco Research Laboratories Private Ltd.), Ethanol(Chong Yu Hitech Chemicals China), Potassium Hydroxide(Himedia Laboratories Private Ltd.), Sulphuric acid (Merck Life Sciences Private Ltd.).Distilled water is used for dilution of chemicals and washing of glass apparatus.

\subsection{CNSL extraction from Cashew Nut Shell}

$55 \mathrm{gm}$ of washed, dried, and crushed cashew nutshell was charged into the thimble of the Soxhlet extractor. $250 \mathrm{~mL}$ of $\mathrm{n}$-Hexane was used as a solvent for extraction. The apparatus was set for 4 hours to ensure complete extraction of solvent. The extracted biomass was dried at $75^{\circ} \mathrm{C}$ in a hot air oven. Boiling point of $\mathrm{n}$-hexane is $68^{\circ} \mathrm{C}$. This method was repeated 4 times with fresh biomass to obtain $\sim 180 \mathrm{gms}$ of biomass. The dried biomass was further crushed and separated using sieve analysis. CNSL is extracted from the raffinate by simple distillation

The hexane-CNSL mixture is collected into a round bottom flask placed on a heating mantle. The round bottom flask is connected to a spiral condenser using a right-angled adapter. A collecting conical flask is 
placed at the receiving end of the condenser to collect the distillate (hexane). Cooling water is supplied to the spiral condenser. The mixture is heated to $75^{\circ} \mathrm{C}$. Boiling point of $\mathrm{n}$-hexane is $68^{\circ} \mathrm{C}$; hence the hexane distills and is collected in the conical flask. The hexane-free CNSL is poured into an air tight glass vessel for further use(Smith Jr et al. 2003; Subbarao et al. 2011; Anang et al. 2019)

\subsection{Synthesis of catalyst}

The crushed CNS was weighed $(20 \mathrm{gm})$ and charged into a muffle furnace under constant Nitrogen supply for duration of the reaction time. After the reaction time, the char was removed into an air-tight container. $10 \mathrm{gm}$ of biochar was dried in a hot air oven at $105^{\circ} \mathrm{C}$ for 10 minutes. The biochar was then placed into a stoppered conical flask. $100 \mathrm{~mL}$ of concentrated $\mathrm{H}_{2} \mathrm{SO}_{4}$ was carefully added into the conical flask and closed using the stopper. The flask is gently shaken to ensure proper mixing of biochar and acid. The flask with its contents was placed into a muffle furnace preheated to the required temperature. Activation is allowed for 1 hour, after which the flask is removed and allowed to cool at room temperature. The biochar-acid mixture is poured into centrifuge tubes. The mixture is separated in a centrifuge machine at 3000 RPM. The liquid layers are removed, and the remaining catalyst is diluted with hot distilled water and shaken. The mixture is again set to separate in the centrifuge machine. This process was repeated 4 times. Finally, the catalyst was separated from the water through the process of filtration. The catalyst was allowed to dry in a hot air oven at $105^{\circ} \mathrm{C}$ for 1 hour and was put into an airtight vessel to prevent moisture absorption(Yu et al. 2011; Kastner et al. 2012; Chellappan et al. 2018; Yasodhara et al. 2021).

\subsection{Catalyst Characterization}

The physical and chemical characterization of prepared catalyst is evaluated using different techniques like BET method used to study the surface area, pore volume and pore size of catalyst. Hitachi TGA Thermogravimetric analyzer was used to investigate thermochemical degradation behavior. X-ray powdered diffraction(XRD) was performed to find $2 \theta$ angle by scanning $4-80^{\circ}$, FTIR (JASCO-4100) and Elemental analyzer.

\subsection{Synthesis of Biodiesel}

\subsubsection{Esterification Reaction}

Esterification of CNSL was conducted at atmospheric pressure in a batch reactor consisting of a $250 \mathrm{Ml}$ two neck round-bottomed flask with a spiral refluxing condenser, thermometer, and a hot plate with a magnetic stirrer. In a typical experiment, a specified amount of oil was preheated to $105^{\circ} \mathrm{C}$ for 15 minutes for moisture removal. During this process, a specified amount of methanol and catalyst were mixed thoroughly. The temperature of the CNSL was brought down to the required temperature and the methanol-catalyst mixture was poured and the condenser was set. The mixture was refluxed at the desired temperature for a specified amount of time with simultaneous stirring at 400 RPM. The mixture was reheated to $70^{\circ} \mathrm{C}$ for removing excess methanol. The Acid Value of the esterified oil was determined using $\mathrm{NaOH}$. The calculation for conversion is given below(Marchetti and Errazu 2008; Guo et al. 2021) 


$$
\text { FFAConversion } \%=\frac{\text { FFAi }- \text { FFAf }}{\text { FFAi }}
$$

Where $\mathrm{FFA}_{\mathrm{i}}$ is the initial Acid Value and

FFA $_{f}$ is the final Acid Value

Approximate FFA \% = Acid Value/1.99

The optimum process parameters were taken for the comparative study of the conventional acid catalyst and the prepared catalyst.

\subsubsection{Transesterification Reaction}

After reducing the acid value of CNSL through the process of esterification, Biodiesel was produced by transesterification of the parent oil using a conventional base catalyst. The optimum process parameters was adopted in the comparative study of the catalyst as a catalyst for transesterification.

A specified amount of methanol and catalyst were mixed together and poured into a two neck round bottom flask containing the esterified CNSL. A thermometer was placed to measure and control the reaction temperature. The round bottom was set with a spiral reflux condenser onto a heated magnetic stirrer for the duration of the reaction time. After completion of the reaction, the glycerin layer was allowed to separate from the FAME layer in a separating funnel overnight. The glycerin layer was removed and discarded. The FAME layer was heated to $70^{\circ} \mathrm{C}$ to remove any excess methanol and then thoroughly washed in heated distilled water to remove impurities like soap, catalyst, and glycerol. The biodiesel was heated to above $100^{\circ} \mathrm{C}$ to remove any moisture traces and stored in an air-tight container. The yield of Biodiesel was determined by the equation(Khan et al. 2020; Munawar and Manurung 2020; Yusuff and Adesina 2020):

$$
\text { Biodieselyield }(w t \%)=\frac{\text { WeightofpurifiedBiodiesel }}{\text { Weightofrawoilused }} \times 100
$$

2

\section{Result And Discussion}

\subsection{Characterization of catalyst}

Elemental analysis of the catalyst was conducted and compared with that of the precursor biochar. The results are tabulated in Table 1. From the table, we can infer that as the reaction temperature increases, quantity of sulphur present in the catalyst reduced. There is also a decrease in carbon and hydrogen implying the release of $\mathrm{C}-\mathrm{H}$ gas. The higher quantities of $\mathrm{S} \%$ is a desired result of the activation. We can infer that acid groups have adhered to the surface of the catalyst(Chellappan et al. 2018). 
Table 1

Elemental Analysis of Biochar and Catalysts

\begin{tabular}{|lllllllll|}
\hline SI. No & Sample Name & N\% & C\% & S\% & H\% & O\% & H/C & O/C \\
\hline 1. & Biochar $1 \mathrm{hr}$ & 1.22 & 62.41 & 1.07 & 3.81 & 31.49 & 0.061 & 0.504 \\
\hline 2. & Catalyst $90^{\circ} \mathrm{C}$ & 0.90 & 51.15 & 6.24 & 3.38 & 38.33 & 0.066 & 0.749 \\
\hline 3. & Catalyst $200^{\circ} \mathrm{C}$ & 0.71 & 42.74 & 1.13 & 0.31 & 55.11 & 0.007 & 1.289 \\
\hline
\end{tabular}

Lower $\mathrm{S} \%$ content in the catalyst activated at $200^{\circ} \mathrm{C}$ could be explained due to the fluctuating temperature in the furnace and improper mixing of the acid during activation procedure(Kastner et al. 2012).

Table 2

Functional groups present in biochar-catalyst

\begin{tabular}{|ll|}
\hline Wavenumber $\left(\mathrm{cm}^{-1}\right)$ & Functional Group \\
\hline 572.1 & Aromatic $\mathrm{CH}$ Bending \\
\hline 1019.4 & $-\mathrm{SO}_{2}-$ symmetric stretching \\
\hline 1131.2 & $-\mathrm{SO}_{3} \mathrm{H}$-asymmetric stretching \\
\hline 1578.5 & Carboxylic Acid $\mathrm{C}=0$ symmetric Stretch \\
\hline
\end{tabular}

TGA analysis of the catalysts were performed in the presence of $\mathrm{N}_{2}$. The weight $\%$ vs increasing temperature of each catalyst was plotted for comparison as shown in Figure 1. The initial $10-15 \%$ loss of weight is attributed to the free moisture and water desorption. After which there is slight plateau between $100-250^{\circ} \mathrm{C}$ thereafter a slow and steady weight loss occurs. Overall the samples lost $49 \%$ and $46 \%$ of their overall mass for catalyst prepared at $90^{\circ} \mathrm{C}$ and $200^{\circ} \mathrm{C}$ respectively.

FTIR spectroscopy was conducted on samples of both catalysts. The spectrum was plotted for comparison as shown in Figure 2 Comparison of the plots infers that no addition functional groups have been found in the catalyst activated at $200^{\circ} \mathrm{C}$. The functional groups found in $\mathrm{t}(\mathrm{Lim}$ et al. 2020; Wang et al. 2020; Satapute et al.)he catalyst are provided Table 2.

The catalysts exhibited the typical bands of carbonyl groups $\left(C=0\right.$, at $\left.1578 \mathrm{~cm}^{-1}\right)$ and characteristic peaks of incompletely carbonized materials, near $572 \mathrm{~cm}^{-1}$ attributable to aromatic ring modes. The appearance of additional bands at $1094 \mathrm{~cm}^{-1}$ (SO2 stretching) and $1131 \mathrm{~cm}^{-1}$ (stretching in -SO3H-) in the FTIR spectra of the sulfonated carbons were consistent with the presence of $-\mathrm{SO} 3 \mathrm{H}$ - groups. The higher peak intensities of -SO2- and -SO3H- correspond to the activation yield of the catalyst(Lim et al. 2020; Wang et al. 2020; Satapute et al.).

XRD analysis was conducted on both the catalyst. The graph of XRD confirms that both catalyst is amorphous in nature devoid of any crystalline compound or group present on the catalyst surface. The 
XRD plot is shown in Figure 3 and 4 for catalyst produced at $90^{\circ} \mathrm{C}$ and $200^{\circ} \mathrm{C}$.

The catalyst shows diffraction peaks at $2 \theta$ range of $15-30^{\circ}$ region, which indicates that of an amorphous carbon structure with randomly oriented aromatic carbon sheets(Wang et al. 2017).

Through these characterization techniques, it was determined that the catalyst produced at $90^{\circ} \mathrm{C}$ contained the ideal functional groups and properties for biodiesel production from CNSL.

BET analysis was conducted on the catalyst and the surface area was found to be $35.429 \mathrm{~m}^{2} / \mathrm{g}$.

\subsection{Esterification Parameter Studies}

\subsubsection{Influence of Catalyst Weight and Reaction time}

Esterification was conducted in a round bottom flask heated on a magnetic stirrer with the use of spiral condenser for reflux. The methanol to oil ratio, reaction temperature and stirring rate were kept constant at $25: 1,65^{\circ} \mathrm{C}$ and $600 \mathrm{RPM}$ respectively. The reaction time was incremented every $60 \mathrm{mins}$. The catalyst weight utilized for the esterification were $15 \mathrm{w} / \mathrm{w} \%, 16 \mathrm{w} / \mathrm{w} \%, 17 \mathrm{w} / \mathrm{w} \%, 18 \mathrm{w} / \mathrm{w} \%, 19 \mathrm{w} / \mathrm{w} \%, 20 \mathrm{w} / \mathrm{w} \%$ and $25 \mathrm{w} / \mathrm{w} \%$. The graph of the FFA conversion \% with respect to reaction time is plotted in Figure 5.From the graph we can infer that for lower catalyst weight $(15 \mathrm{w} / \mathrm{w} \%)$ there is a sharper increase in percentage conversion of FFA with initial conversion (at $60 \mathrm{mins}$ ) of $18.6 \%$ and final conversion (at $240 \mathrm{mins}$ ) of $\sim 40 \%$. It is also observed that for increased catalyst weight the initial and final conversion of FFA increased. For higher catalyst weight, though conversion of FFA, the rate of conversion is lower when compared to using low catalyst weight. Highest conversion was achieved at 240 mins of catalyst weight of $25 \mathrm{w} / \mathrm{w} \%$ of $80.35 \%$.

Using the optimum parameters for esterification while keeping methanol to oil, reaction temperature and stirring rate constant, esterification was carried out for the two types of catalyst i.e. homogeneous and heterogeneous catalyst. Esterification reaction was performed with reaction temperature at $65^{\circ} \mathrm{C}$ and rotational Speed was 600RPM. The homogeneous $\left(\mathrm{H}_{2} \mathrm{SO}_{4}\right)$ and heterogeneous (biochar catalyst) was taken are $25 \mathrm{w} / \mathrm{w} \%$. Methanol to oil ratio was kept constant at $30: 1$

The graph of the comparison study is shown in Figure 6. From the graph we can infer that the effectiveness of the biochar-catalyst is lesser than that of the conventional catalyst $\mathrm{H}_{2} \mathrm{SO}_{4}$. The highest FFA conversion using biochar catalyst was achieved at 240 mins with $74.57 \%$ conversion of FFA present in CNSL. It must be noted that longer the reaction time for esterification, the higher the conversion $\%$ of FFA(Lim et al. 2020).

\subsubsection{Influence of Methanol to Oil ratio and Reaction Time}

Esterification was conducted in a round bottom flask heated on a magnetic stirrer with the use of spiral condenser for reflux. The catalyst weight, reaction temperature and stirring rate were kept constant at $20: 1,65^{\circ} \mathrm{C}$ and $600 \mathrm{RPM}$ respectively. The reaction time was incremented every $60 \mathrm{mins}$. The methanol to 
oil ratio utilized for the esterification were 10:1, 14:1, 18:1, 22:1, 26:1, 30:1, 34:1. The graph of the FFA conversion \% with respect to reaction time is plotted in Figure 7.

From Figure 7, it can be observed that larger the ratio of methanol to oil, results in higher FFA conversion, therefore higher amounts of methanol will be required to cause significant conversion of FFA. Higher FFA conversion was achieved at $89.3 \%$ for 240 mins reaction time and for methanol to oil ratio of $30: 1$.

Whereas when 34:1 methanol to oil was used there was lesser conversion of FFA. This can be explained using Le Chatlier's principle, where the increase in the reactant (methanol: oil) causes increase product formation (biodiesel and water).

From the previous study, while keeping the catalyst weight, reaction temperature and stirring rate constant at optimum conditions i.e. $20 \mathrm{w} / \mathrm{w} \%, 65^{\circ} \mathrm{C}$ and $600 \mathrm{RPM}$ respectively. Catalyst used here was homogenous $\left(\mathrm{H}_{2} \mathrm{SO}_{4}\right)$ and heterogeneous (biochar catalyst). The methanol to oil ratio was taken as 30:1 as determined by parameter study. The graph of the comparison study is shown in Figure 8.

From the graph we can infer that the effectiveness of the biochar-catalyst is lesser than that of the conventional catalyst $\mathrm{H}_{2} \mathrm{SO}_{4}$. The highest FFA conversion using biochar catalyst was achieved at 240 mins with $77.57 \%$ conversion of FFA present in CNSL.

\subsubsection{Influence of Reaction temperature and Reaction Time}

To comprehend the relationship between the reaction temperature and FFA conversion \%, esterification reaction was conducted keeping catalyst weight, methanol to oil ratio and stirring rate constant at $20 \mathrm{w} / \mathrm{w} \%, 30: 1$ and $600 \mathrm{RPM}$ respectively. The reaction time was incremented by $60 \mathrm{mins}$. The reaction temperature was varied from $50^{\circ} \mathrm{C}$ to $65^{\circ} \mathrm{C}$ incremented by $5^{\circ} \mathrm{C}$. The resulting reduction in FFA conversion $\%$ was plotted against reaction time as shown in Figure 9.

Esterification was conducted at optimum conditions of methanol to oil ratio, catalyst weight previous parameter study, with varying reaction temperature.

During esterification at $40^{\circ} \mathrm{C}$, FFA conversion was very low even after reaction time of $240 \mathrm{mins}$. This demonstrates the significance of reaction temperature to the FFA conversion. When the reaction temperature was increased, a higher FFA conversion was observed. Highest conversion of $88.1 \%$ was observed at $65^{\circ} \mathrm{C}$ for 240 mins reaction time.

\subsubsection{Comparison of FFA conversion using heterogeneous and homogeneous catalyst}

To compare the effectiveness of biochar catalyst in the study of reaction temperature to the conversion of FFA, optimum parameter were selected for the esterification where, methanol to oil ratio, catalyst weight and stirring rate were kept constant at 30:1, $20 \mathrm{w} / \mathrm{w} \%$ and 600RPM respectively. The reaction 
temperature was kept constant at $65^{\circ} \mathrm{C}$ for esterification reaction using both catalyst. The results of FFA conversion is shown in Figure 10. The comparison study of the catalyst in the esterification study of reaction time to the FFA conversion demonstrates that the homogeneous catalyst is more effective in FFA conversion of CNSL.

Although the biochar catalyst produced provided adequate conversion of $75 \%$. It can be inferred from the above studies that the biochar catalyst when used as an acid catalyst for the esterification of CNSL (for the reduction is FFA) was able to achieve a maximum conversion $\sim 77 \%$ under optimum conditions. Although utilization of conventional acid catalyst of $\mathrm{H}_{2} \mathrm{SO}_{4}$ yielded higher results of $\sim 90 \%$ conversion of FFA.

Esterification was repeated under the optimum conditions for homogeneous catalyst for the preparation of esterified oil. The esterified oil was allowed to settle in a separating funnel and the bottom by-product layer was removed. The upper layer of esterified oil was heated to $70^{\circ} \mathrm{C}$ to remove any excess methanol. The esterified oil was used for the transesterification study using conventional homogeneous catalyst $\mathrm{KOH}$ and biochar- catalyst.

\subsection{Transesterification Parameter Studies}

The process parameters for maximum yield of FFA conversion was repeated till $\sim 1000 \mathrm{ml}$ of esterified oil was obtained. The esterified oil (acid value $8.59 \mathrm{mgKOH} / \mathrm{g}$ ) was used for the transesterification reaction using methanol in the presence of conventional homogeneous catalyst aqueous $\mathrm{KOH}$ and heterogeneous biochar catalyst. The parameter study of transesterification was carried out using aqueous $\mathrm{KOH}$. The effectiveness of the biochar catalyst as a transesterification catalyst was compared with optimum parameters are obtained from the parameter study(Wang et al. 2020).

\subsubsection{Influence of methanol: oil ratio on biodiesel production}

Transesterification reaction was conducted in a two necked round bottom flask on a heated magnetic stirrer. The reaction temperature and catalyst weight were kept constant at $65^{\circ} \mathrm{C}$ and $1.0 \mathrm{w} / \mathrm{w} \%$ respectively. The reaction was conducted for 1 hour. The methanol to oil ratio was increased four times for each study. The contents were allowed to settle in a separating funnel and the FAME layer was removed and purified. The weight of the purified biodiesel was compared to esterified CNSL to obtain yield. The results for the transesterification are available in Figure 11. The reaction yield is shown to increase steadily on the increase of alcohol ratio in the biodiesel production. It was observed that the biodiesel yield stabilized at higher ratios (as seen at 16:1 and 20:1). Maximum biodiesel yield was obtained at $20: 1$ ratio of $85.4 \%$. 
Table 3

Comparison of catalyst in biodiesel

yield for methanol to oil study

\begin{tabular}{|ll|}
\hline Reaction Yield\% & Catalyst \\
\hline 85.4 & KOH Catalyst \\
\hline 24.9 & Biochar Catalyst \\
\hline
\end{tabular}

Transesterification study was conducted using biochar catalyst at process parameters of $65^{\circ} \mathrm{C}$ reaction temperature, 1 hour reaction time, $1 \mathrm{w} / \mathrm{w} \%$ of catalyst at 20:1 methanol to oil ratio. The comparison of the biodiesel yield is provided in Table 3 . The yield of biodiesel using the biochar catalyst is significantly lesser when compared to the conventional catalyst.

\subsubsection{Influence of catalyst weight on biodiesel production}

Transesterification reaction was conducted in a two necked round bottom flask on a heated magnetic stirrer. The reaction temperature and time were kept constant at $65^{\circ} \mathrm{C}$ and 1 hour respectively. The methanol to oil ratio was taken at 18:1 and the catalyst weight incremented by 5 for each reaction study. The contents were allowed to settle in a separating funnel and the FAME layer was removed and purified. The weight of the purified biodiesel was compared to esterified CNSL to obtain yield. The results for the transesterification are available in Figure 12.

The biodiesel production in the very first study yield high values. Further increase of catalyst weight showed a marginal increase in biodiesel yield. The maximum yield was obtained at $5 \mathrm{w} / \mathrm{w} \%$ of $94.6 \%$ biodiesel.

Transesterification study was conducted using biochar catalyst at process parameters of $65^{\circ} \mathrm{C}$ reaction temperature, 1 hour reaction time, $5 \mathrm{w} / \mathrm{w} \%$ of catalyst at $18: 1$ methanol to oil ratio. The comparison of the biodiesel yield has been provided in Table 4. The yield of biodiesel using the biochar catalyst is comparably higher when increasing the catalyst weight when compared to the results obtained in Table 4.

Table 4

Comparison of catalyst in biodiesel yield for catalyst weight study

\begin{tabular}{|ll|}
\hline Reaction Yield\% & Catalyst \\
\hline 93.3 & KOH Catalyst \\
\hline 37.2 & Biochar Catalyst \\
\hline
\end{tabular}

\subsubsection{Influence of Reaction time in the study of biodiesel production}


Transesterification reaction was conducted in a two necked round bottom flask on a heated magnetic stirrer. The reaction temperature, catalyst weight and methanol to oil ratio were kept constant at $65^{\circ} \mathrm{C}, 3$ $\mathrm{w} / \mathrm{w} \%$ and 18:1 respectively. The reaction time was incremented every $30 \mathrm{mins}$. The contents were allowed to settle in a separating funnel and the FAME layer was removed and purified. The weight of the purified biodiesel was compared to esterified CNSL to obtain yield. The results for the transesterification are available in Figure 13.

It can be observed from the graph that the reaction time shows the rate of transesterification is higher in the initial $60 \mathrm{mins}$ thereafter there is a marginal increase in biodiesel yield as the reaction time progress. Although maximum yield was obtained at 120 mins of $95.1 \%$ conversion.

Transesterification study was conducted using biochar catalyst at process parameters of $65^{\circ} \mathrm{C}$ reaction temperature, 1 hour reaction time, $3 \mathrm{w} / \mathrm{w} \%$ of catalyst at 18:1 methanol to oil ratio. The yield of biodiesel is shown Figure 13.. It can be inferred from the results that as the reaction time progress the yield of biodiesel increases slightly. It is also observed that there is a faster rate of reaction in the first $60 \mathrm{mins}$ of the transesterification process. There after the reaction rate reduces significantly.

From the transesterification studies it can be inferred that highest conversion of CNSL to biodiesel is achieved through the use of the conventional catalyst $\mathrm{KOH}(94.2 \%)$ and process parameters of $65^{\circ} \mathrm{C}$ reaction temperature, $1 \mathrm{hr}$ reaction time, $18: 1$ methanol to oil ratio and $5 \mathrm{w} / \mathrm{w} \%$ catalyst weight. The highest conversion achieved using the biochar catalyst was $43.4 \%$ at optimum process parameters. It can be inferred that the biochar catalyst is not effective as an acid catalyst for transesterification reaction.

\subsection{Properties analysis of biodiesel}

Samples of the biodiesel was taken to test the chemical and physical properties according to ASTM standards.

The result of the analysis is tabulated in Table 5. 
Table 5

Physical and Chemical Properties Biodiesel

\begin{tabular}{|lll|}
\hline SL No & Properties & Value \\
\hline $\mathbf{1 .}$ & Color & Light Brown \\
\hline 2. & $\mathrm{pH}$ & 4.5 \\
\hline 3. & Kinematic Viscosity & 2.81 \\
\hline 4. & Density $\left(\mathrm{kg} / \mathrm{m}^{3}\right)$ & 860 \\
\hline 5. & Specific Density & 0.859 \\
\hline The properties of Biodiesel tabulated in the Table 5.fall under the required range of biodiesel standard \\
\hline
\end{tabular}

\section{Conclusions}

Transesterification studies were carried out using $\mathrm{KOH}$ and the biochar catalyst. The reaction time, methanol to oil ratio, and catalyst weight were varied individually. A maximum yield of biodiesel of $94.2 \%$ was achieved using $\mathrm{KOH}$ catalyst. The maximum yield of biodiesel using biochar catalyst was recorded at $43.4 \%$. From this study it can be inferred that the biochar catalyst produced from the chemical activation using $\mathrm{H}_{2} \mathrm{SO}_{4}$ is successful as a catalyst in esterification process but is not highly effective as an acid catalyst for transesterification reaction. However study showed cashew nut seed shell is a costeffective and environmentally benign catalyst and a better waste to energy option.

\section{Declarations}

\section{Authors Contributions}

Vanisree G S, Dr. Aparna K created the concept and Ansuya Paleri interpreted the data. conducted the literature survey and carried out the experiments. Graphical design and manuscript preparation by Vanisree G S.

\section{Funding}

Not applicable

\section{Availability of data and materials}

The information will be provided upon request.

\section{Ethical Approval}

Not applicable 


\section{Consent to Participate}

Not applicable

\section{Consent to Publish}

Not applicable

\section{Competing Interests}

The authors declare no competing interests.

\section{Acknowledgments}

The authors would like to thank the Department of Chemical Engineering, National Institute of Technology Calicut (NITC), for the necessary facilities. We would like to thank the Department of Chemistry NITC for FTIR characterization and STIC Kochi for Elemental characterization.

\section{References}

1. Anang MA, Oteng-Peprah M, Opoku-Boadu K (2019) Extraction and characterisation of african star apple (Chrysophyllum albidum) seed oil and the adsorptive properties of the fruit shell in Ghana. International journal of food science 2019

2. Chellappan S, Nair V, Sajith V, Aparna K (2018) Experimental validation of biochar based green Bronsted acid catalysts for simultaneous esterification and transesterification in biodiesel production. Bioresource Technology Reports 2:38-44

3. Chen C, Cai L, Zhang $L$ et al (2020) Transesterification of rice bran oil to biodiesel using mesoporous NaBeta zeolite-supported molybdenum catalyst: experimental and kinetic studies. Chem Eng $\mathrm{J}$ 382:122839

4. Deepanraj B, Senthilkumar N, Mala D, Sathiamourthy A (2021) Cashew nut shell liquid as alternate fuel for $\mathrm{Cl}$ engine-optimization approach for performance improvement.Biomass Conversion and Biorefinery $1-14$

5. Gohain M, Devi A, Deka D (2017) Musa balbisiana Colla peel as highly effective renewable heterogeneous base catalyst for biodiesel production. Ind Crops Prod 109:8-18

6. Guo K (2013) Current issues of fossil fuels and their future prospects. Fossil Fuels: Sources, EnvironmentalConcernsandWasteManagementPractices 85-99

7. Guo M, Jiang W, Chen C et al (2021) Process optimization of biodiesel production from waste cooking oil by esterification of free fatty acids using La3+/ZnO-TiO2 photocatalyst. Energy Conv Manag 229:113745

8. Ishola F, Mamudu AO, Adelekan D et al (2020) Production of biodiesel from palm olein with the aid of methanol and potassium hydroxide catalyst. International Journal of Advanced Science and 
Technology 29:1076-1084

9. Justin Abraham Baby S, Suresh Babu S, Devarajan Y (2021) Performance study of neat biodieselgas fuelled diesel engine. Int J Ambient Energy 42:269-273

10. Kastner JR, Miller J, Geller DP et al (2012) Catalytic esterification of fatty acids using solid acid catalysts generated from biochar and activated carbon. Catal Today 190:122-132

11. Khan IW, Naeem A, Farooq M et al (2020) Catalytic conversion of spent frying oil into biodiesel over raw and 12-tungsto-phosphoric acid modified clay. Renewable Energy 155:181-188

12. Khandan M, Saffarzadeh-Matin S (2020) Green hydrophobization of fume silica: Tailoring of heterogeneous basic catalyst for biodiesel production. J Clean Prod 260:121066

13. Lim S, Yap CY, Pang YL, Wong KH (2020) Biodiesel synthesis from oil palm empty fruit bunch biochar derived heterogeneous solid catalyst using 4-benzenediazonium sulfonate. J Hazard Mater 390:121532

14. Lubi MC, Thachil ET (2000) Cashew nut shell liquid (CNSL)-a versatile monomer for polymer synthesis. Des Monomers Polym 3:123-153

15. Marchetti J, Errazu A (2008) Esterification of free fatty acids using sulfuric acid as catalyst in the presence of triglycerides. Biomass Bioenergy 32:892-895

16. Munawar A, Manurung R (2020) Biodiesel synthesis from refined bleached and deodorized palm oil (RBDPO) by transesterification using durian shell based carbon modified with $\mathrm{KOH}$ as heterogeneous catalyst. IOP Publishing, p 012063

17. Naik BD, Meivelu U (2020) Experimental studies on sodium methoxide supported bentonite catalyst for biodiesel preparation from waste sunflower oil. Environ Prog Sustain Energy 39:e13390

18. Pikula K, Zakharenko A, Stratidakis A et al (2020) The advances and limitations in biodiesel production: feedstocks, oil extraction methods, production, and environmental life cycle assessment. Green Chem Lett Rev 13:275-294

19. Qu T, Niu S, Gong Z et al (2020) Wollastonite decorated with calcium oxide as heterogeneous transesterification catalyst for biodiesel production: Optimized by response surface methodology. Renewable Energy 159:873-884

20. Sahani S, Roy T, Sharma YC (2020) Studies on fast and green biodiesel production from an indigenous nonedible Indian feedstock using single phase strontium titanate catalyst. Energy Conv Manag 203:112180

21. Satapute PP, Patil BN, Kaliwal BInternational Journal of Scientific Research and Reviews

22. Smith R Jr, Malaluan R, Setianto W et al (2003) Separation of cashew (Anacardium occidentale L.) nut shell liquid with supercritical carbon dioxide. Bioresour Technol 88:1-7

23. Subbarao C, Krishna Prasad K, Prasad V (2011) Review on applications, extraction, isolation and analysis of cashew nut shell liquid (CNSL). The Pharma Research Journal 6:21-41

24. Taiwo EA (2015) Cashew Nut Shell Oil-A Renewable and Reliable Petrochemical Feedstock. Advances in Petrochemicals 1:13 
25. Wang S, Zhao C, Shan R et al (2017) A novel peat biochar supported catalyst for the transesterification reaction. Energy Conv Manag 139:89-96

26. Wang Y, Li D, Zhao D et al (2020) Calcium-Loaded Municipal Sludge-Biochar as an Efficient and Stable Catalyst for Biodiesel Production from Vegetable Oil. ACS omega 5:17471-17478

27. Yasodhara Y, Triono S, Kurniawan YS et al (2021) Preparation and evaluation of alpha-cellulose sulfate based new heterogeneous catalyst for production of biodiesel. J Appl Polym Sci 138:49658

28. Yu JT, Dehkhoda AM, Ellis N (2011) Development of biochar-based catalyst for transesterification of canola oil. Energy Fuels 25:337-344

29. Yusuff AS, Adesina OA (2020) Biodiesel Synthesis from Palm Olein Oil Using Anthill as Catalyst. Journal of Chemical Technology and Metallurgy 52:300-306

30. Zhang $P$, Chen $X$, Leng $Y$ et al (2020) Biodiesel production from palm oil and methanol via zeolite derived catalyst as a phase boundary catalyst: An optimization study by using response surface methodology. Fuel 272:117680

\section{Figures}

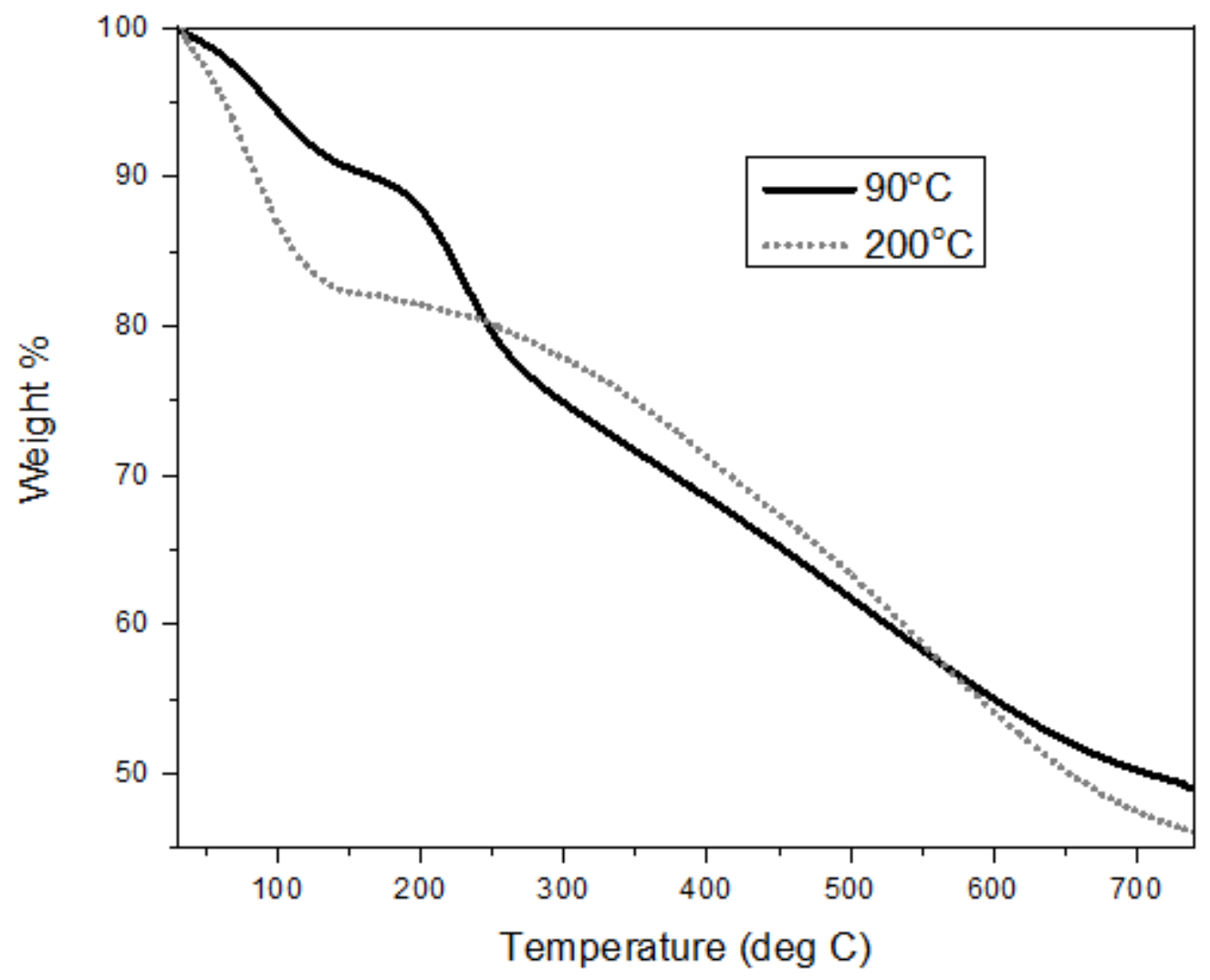

Figure 1

Thermogravimetric analysis of Catalysts 


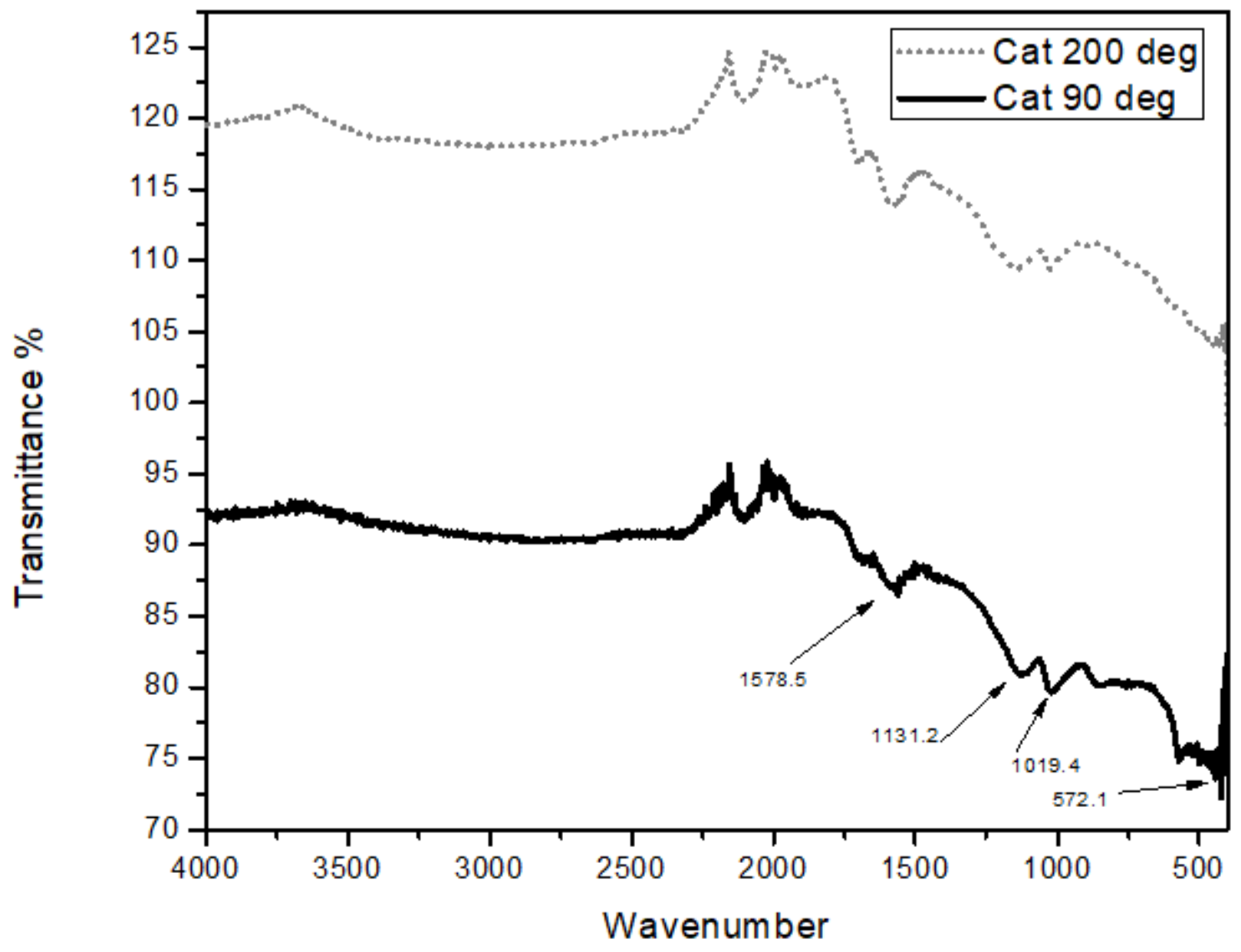

Figure 2

FTIR spectrum analysis of catalysts 


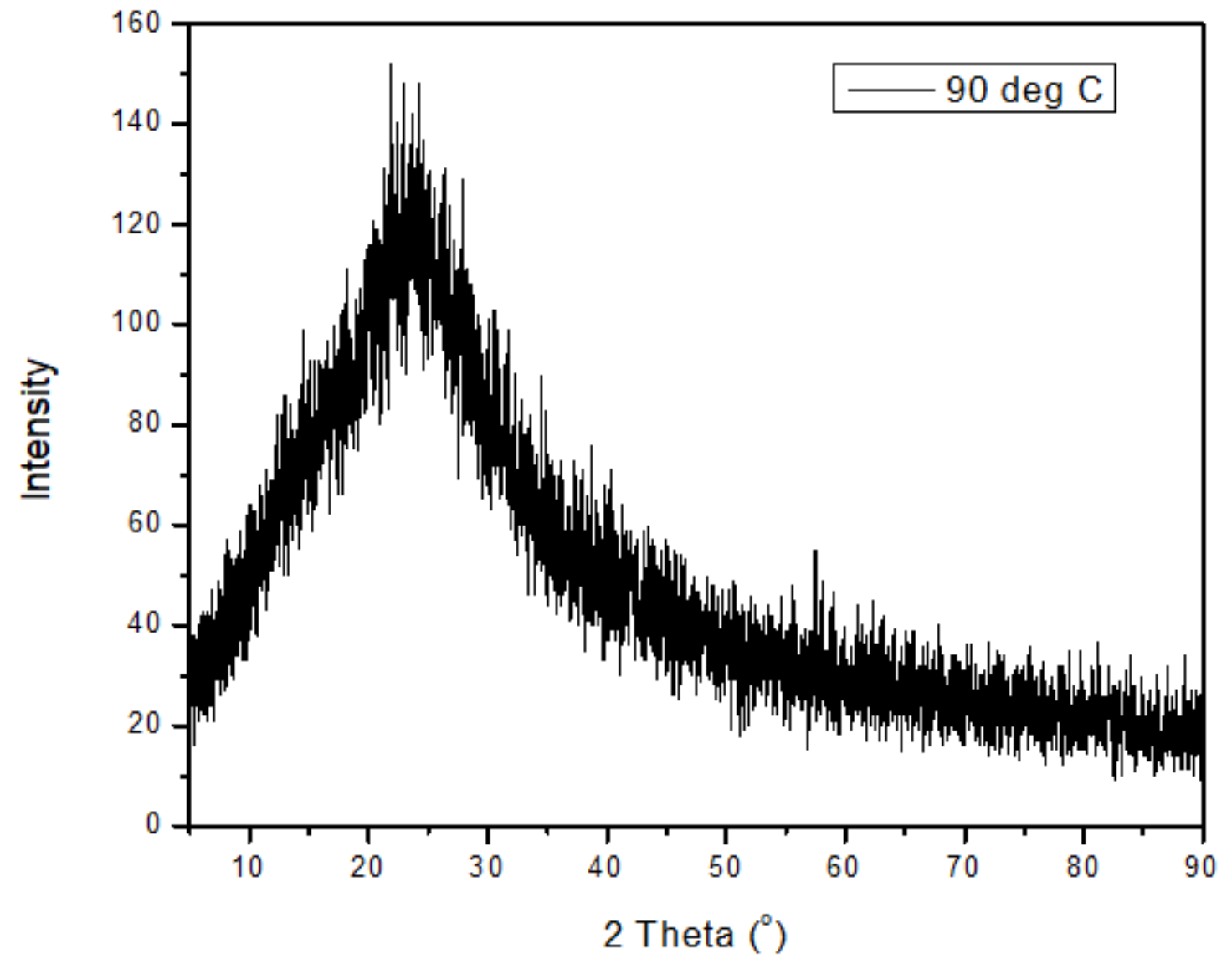

Figure 3

X-Ray Diffraction of Catalyst produced at $90^{\circ} \mathrm{C}$ 


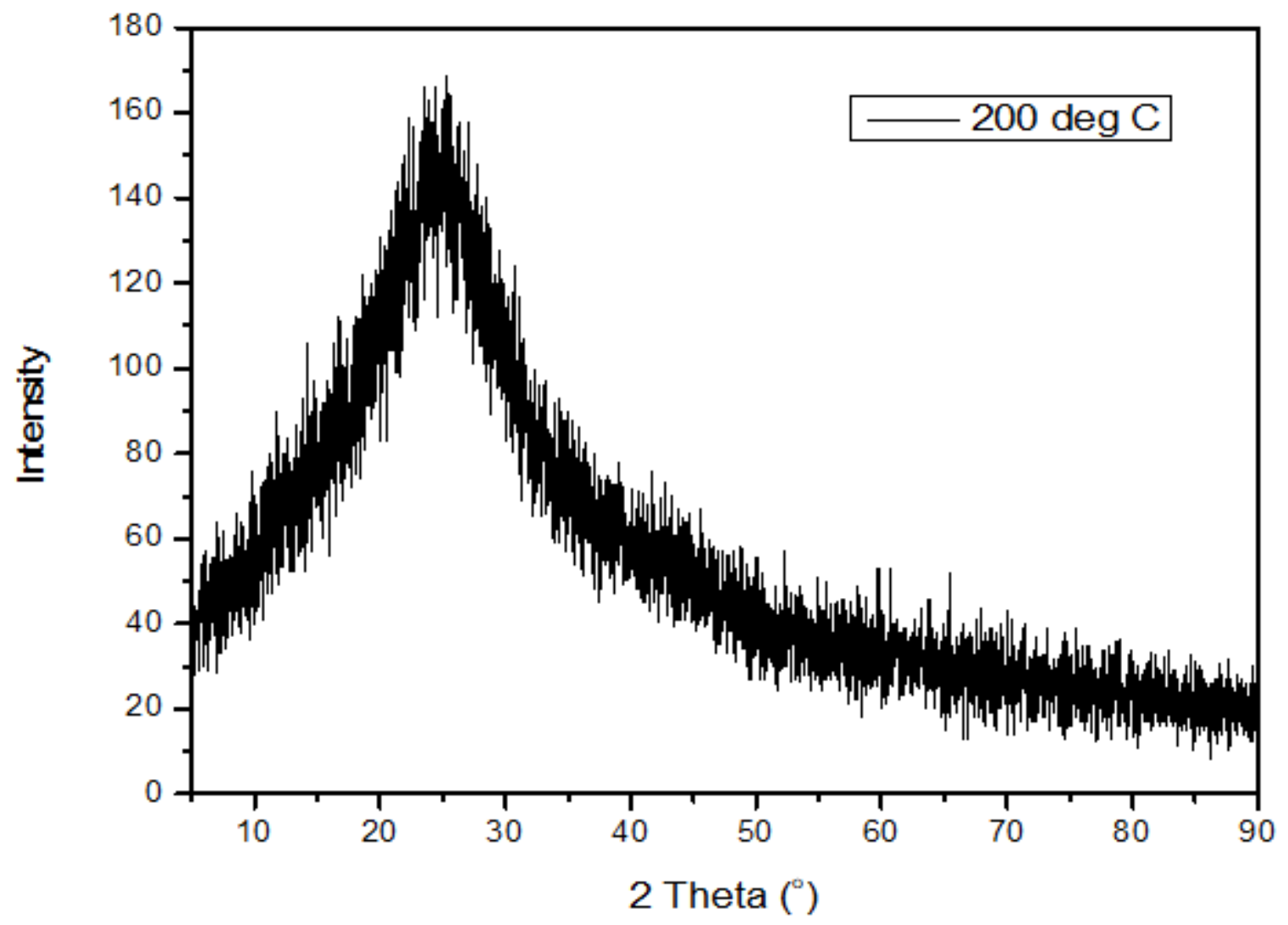

Figure 4

X-Ray Diffraction of Catalyst produced at $200^{\circ} \mathrm{C}$ 


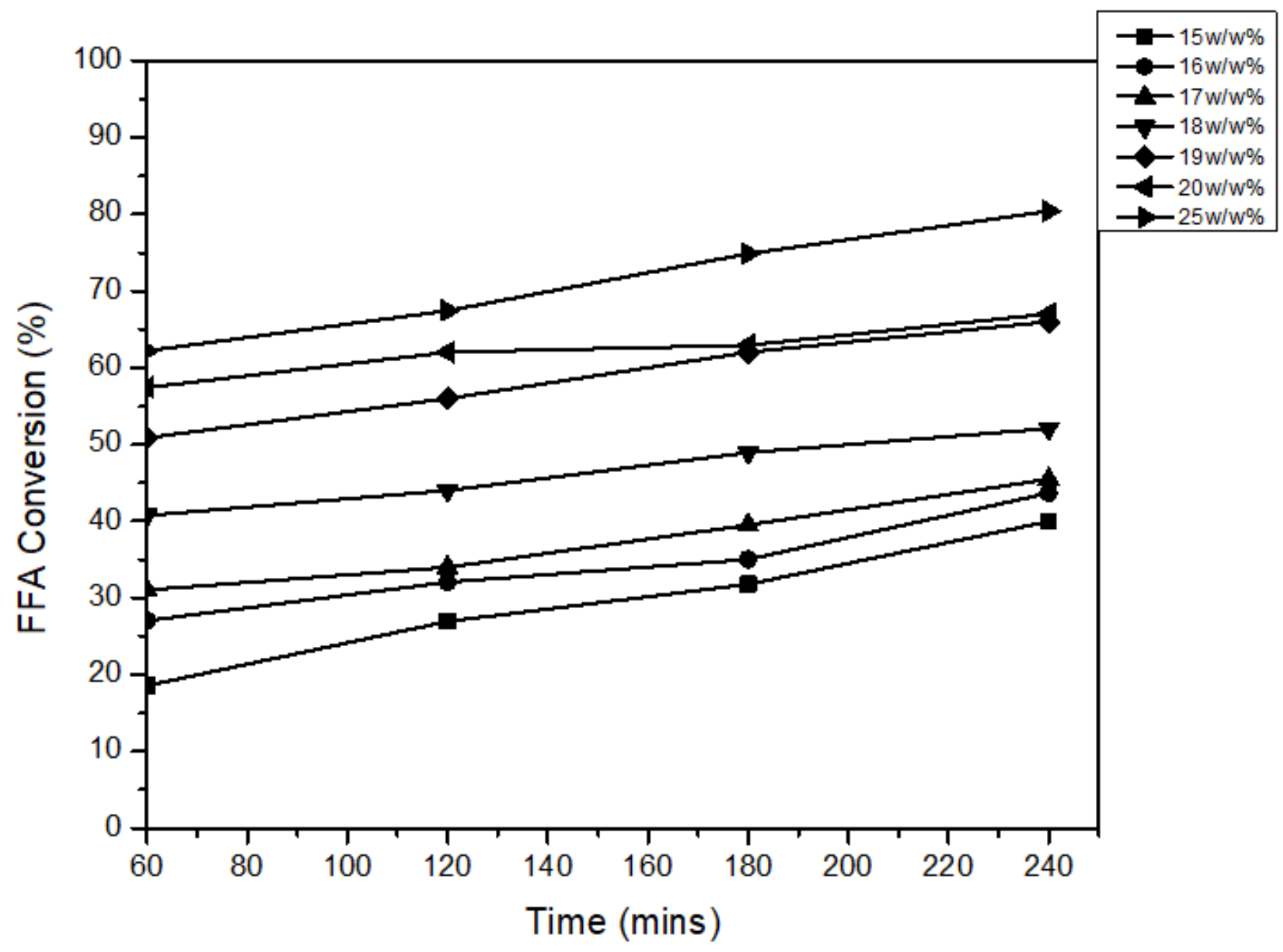

Figure 5

Influence of Catalyst weight and reaction time in the esterification of CNSL 


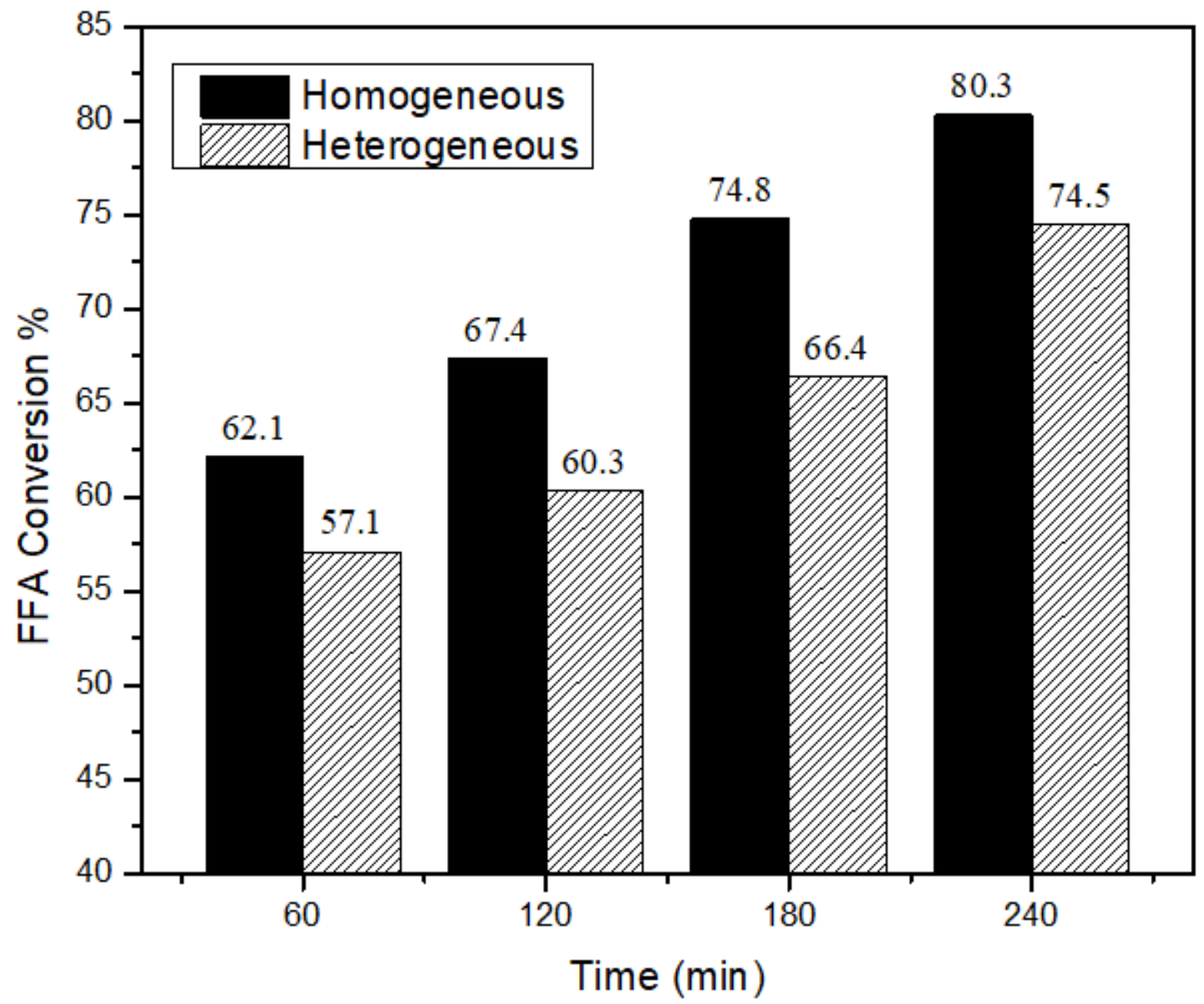

Figure 6

Comparison of $\mathrm{KOH}$ and Biochar catalyst in catalyst weight esterification parameter study 


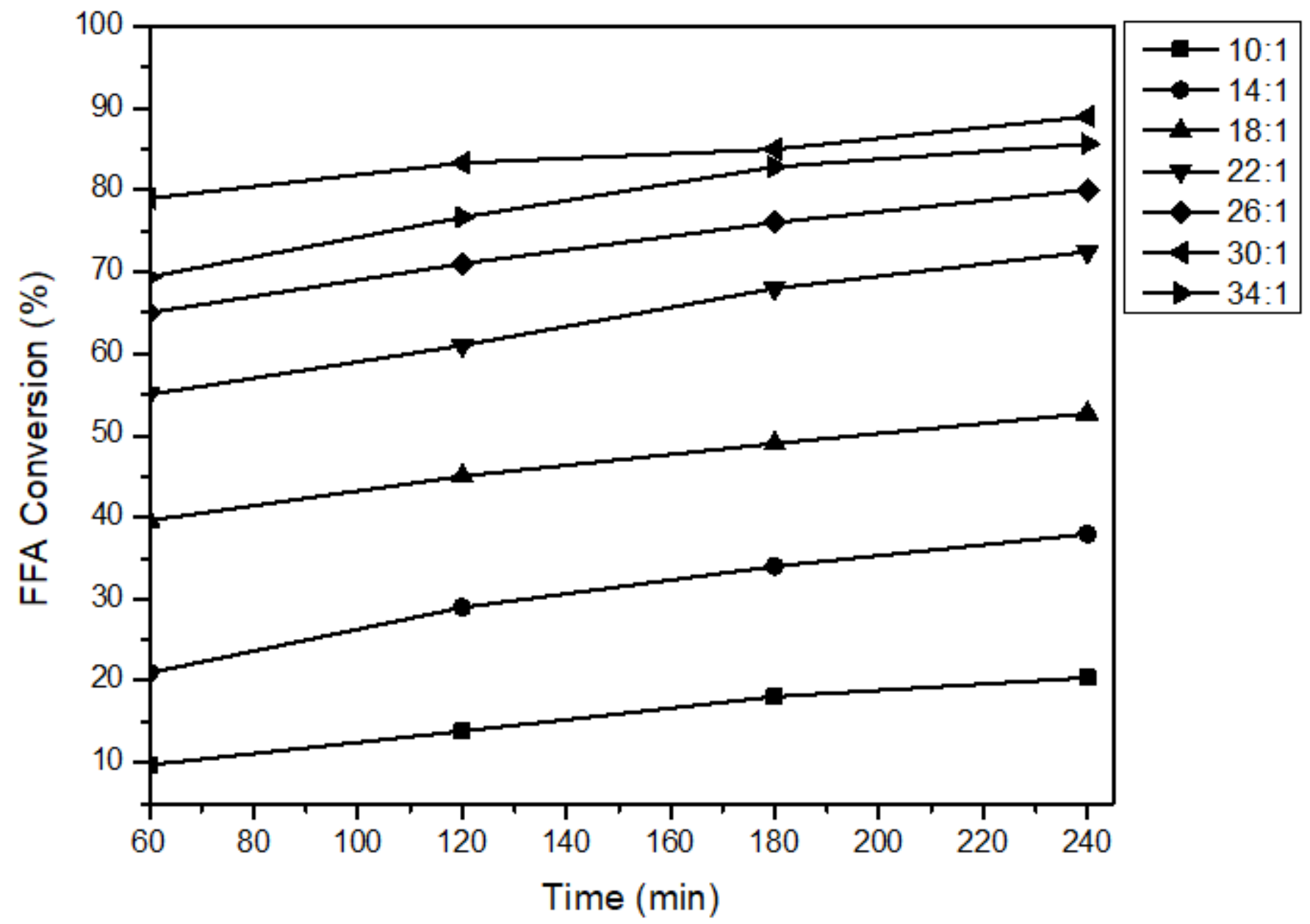

Figure 7

Influence of Methanol to Oil ratio and Reaction Time in the esterification of CNSL 


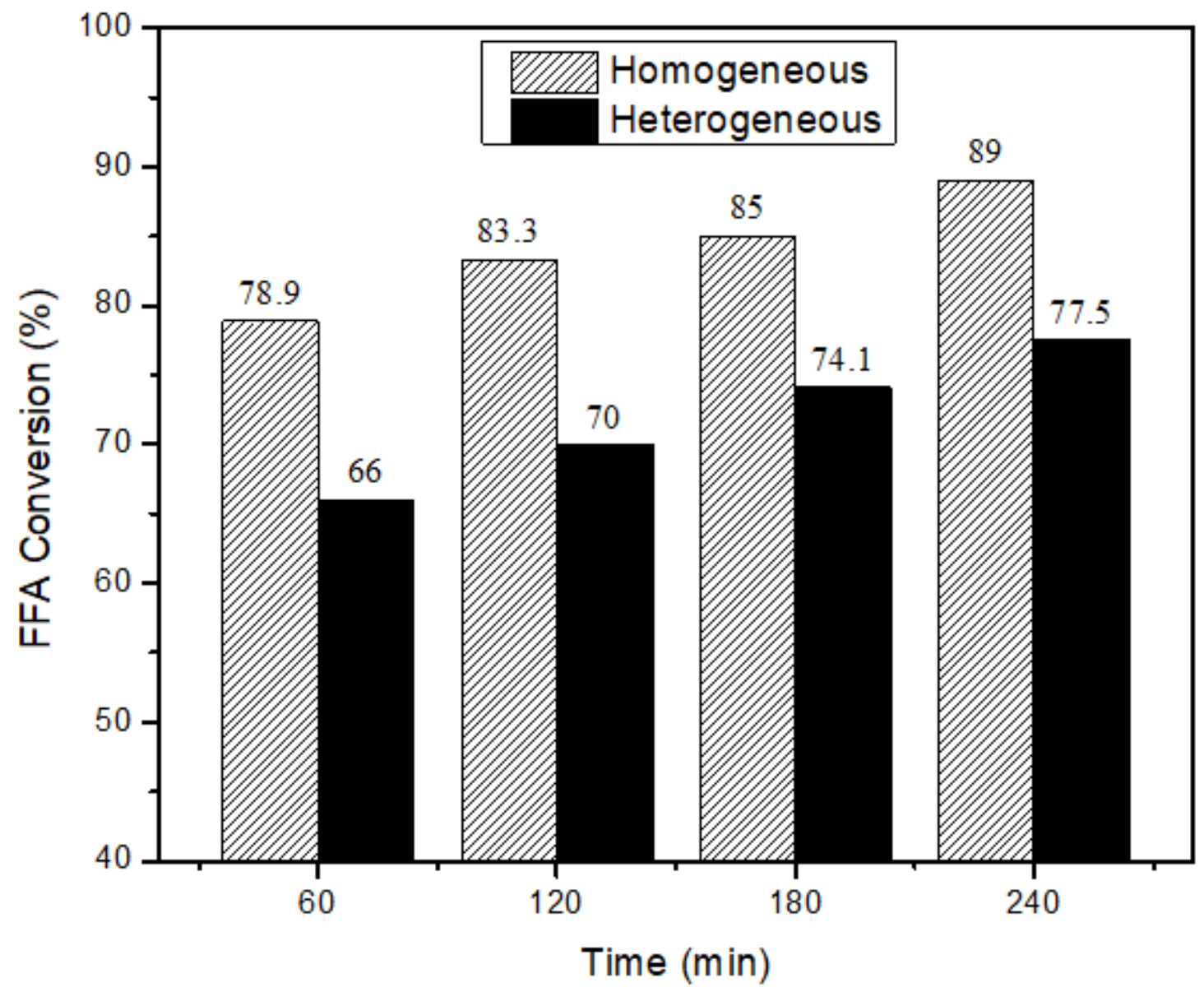

Figure 8

Comparison of $\mathrm{KOH}$ and Biochar catalyst in methanol to oil esterification parameter study 


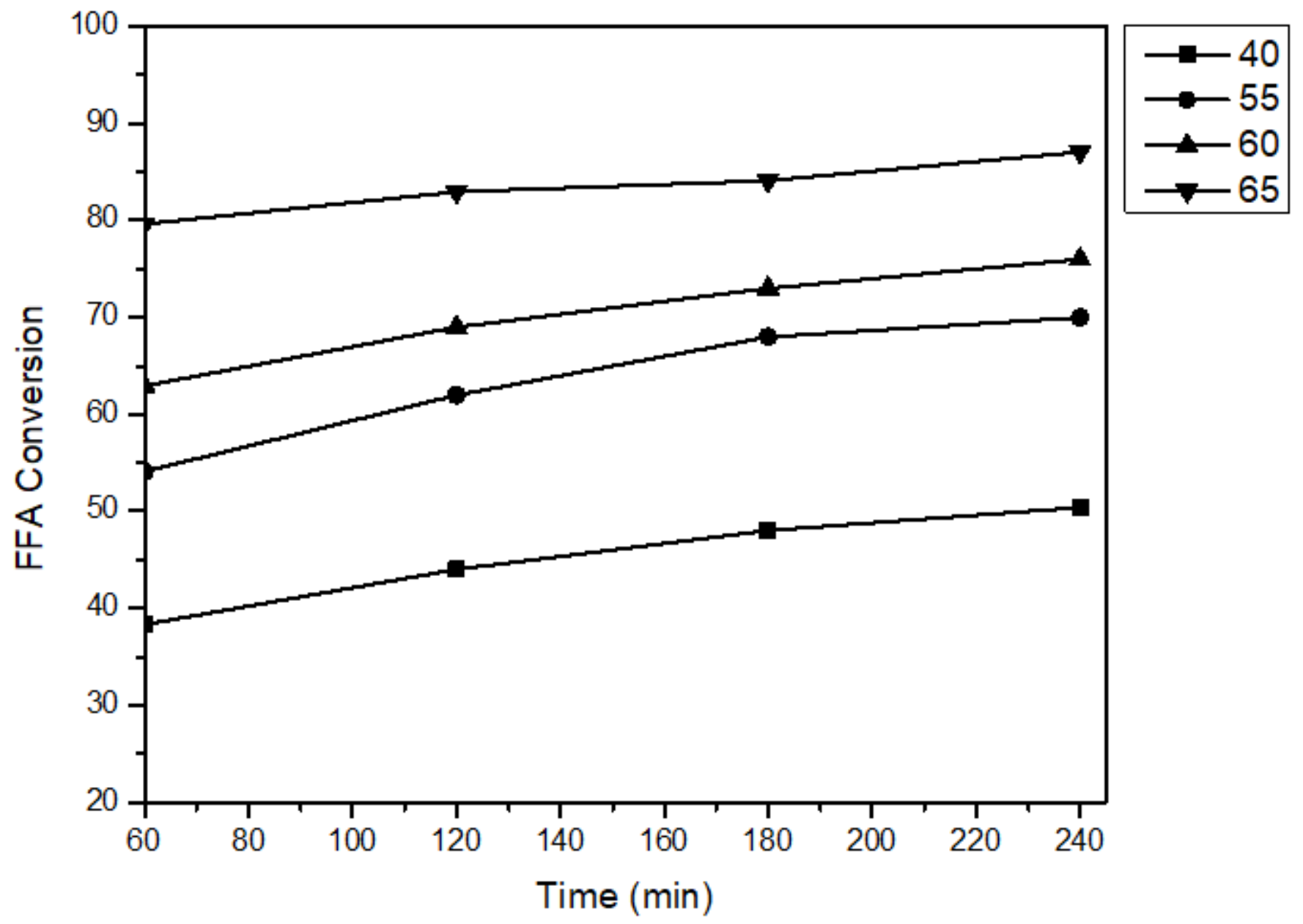

Figure 9

Influence of Reaction temperature and Reaction Time in the esterification of CNSL 


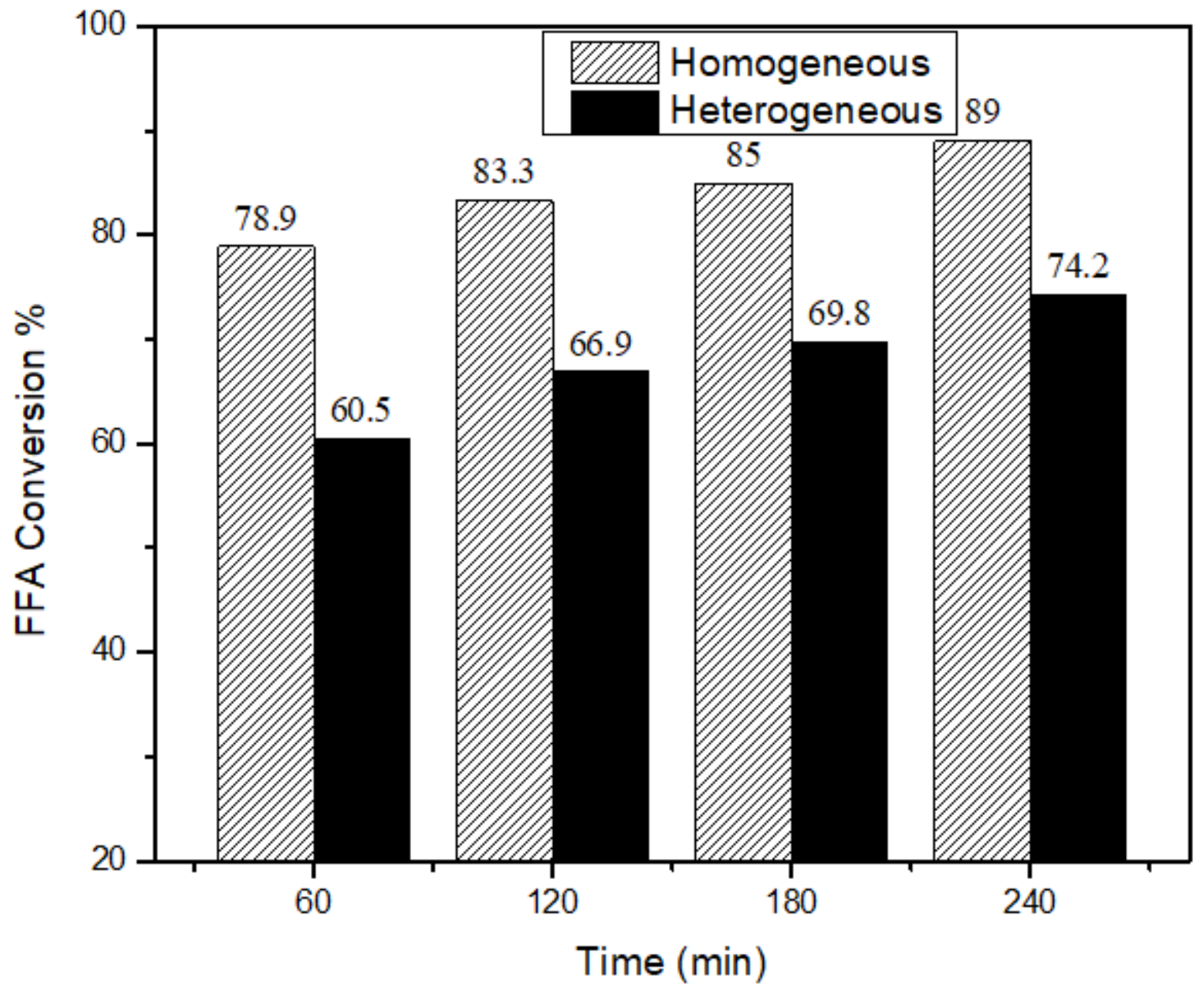

Figure 10

Comparison of $\mathrm{KOH}$ and Biochar catalyst in reaction temperature esterification parameter study 


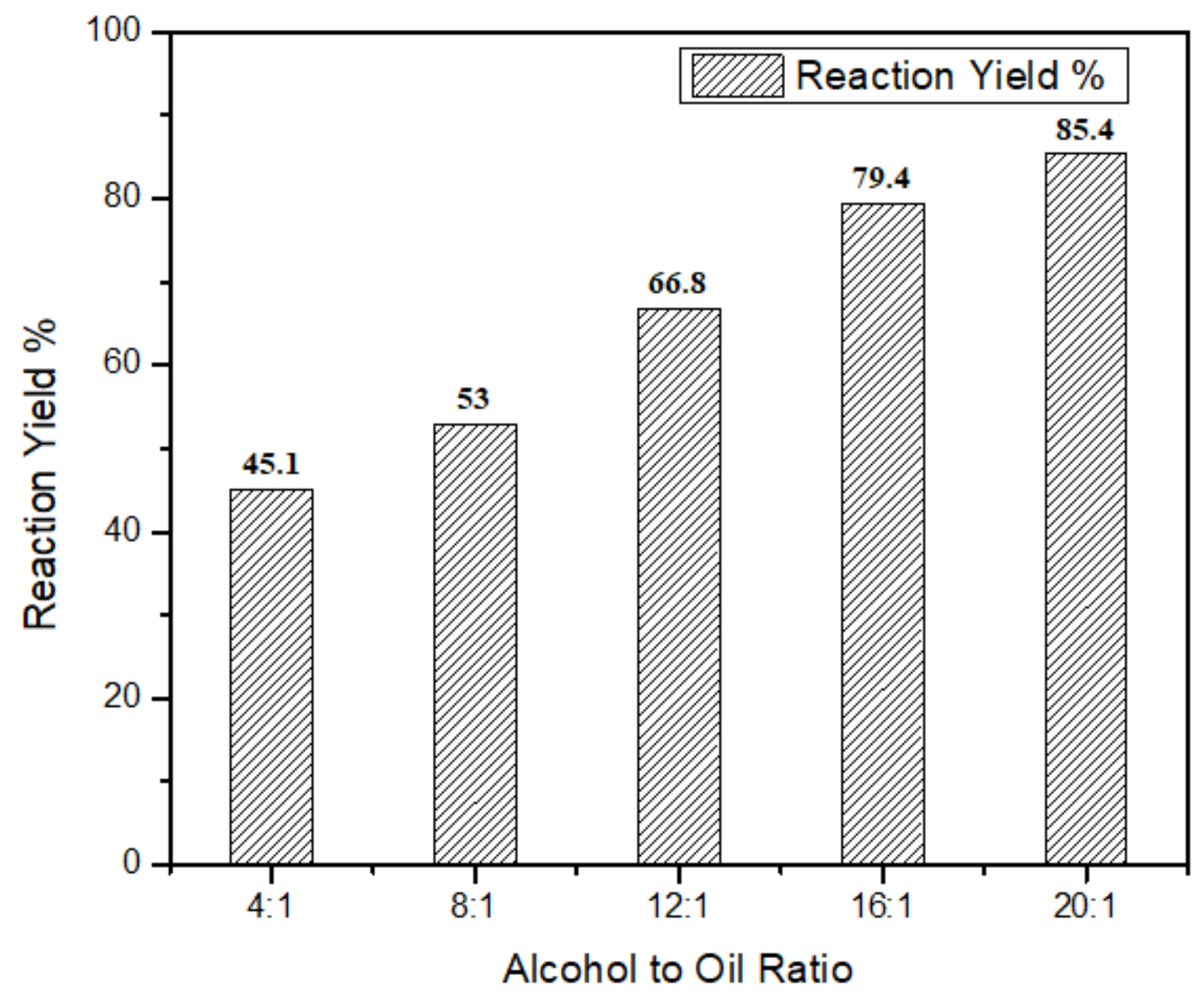

Figure 11

Influence of methanol: oil ratio on biodiesel production using $\mathrm{KOH}$ catalyst 


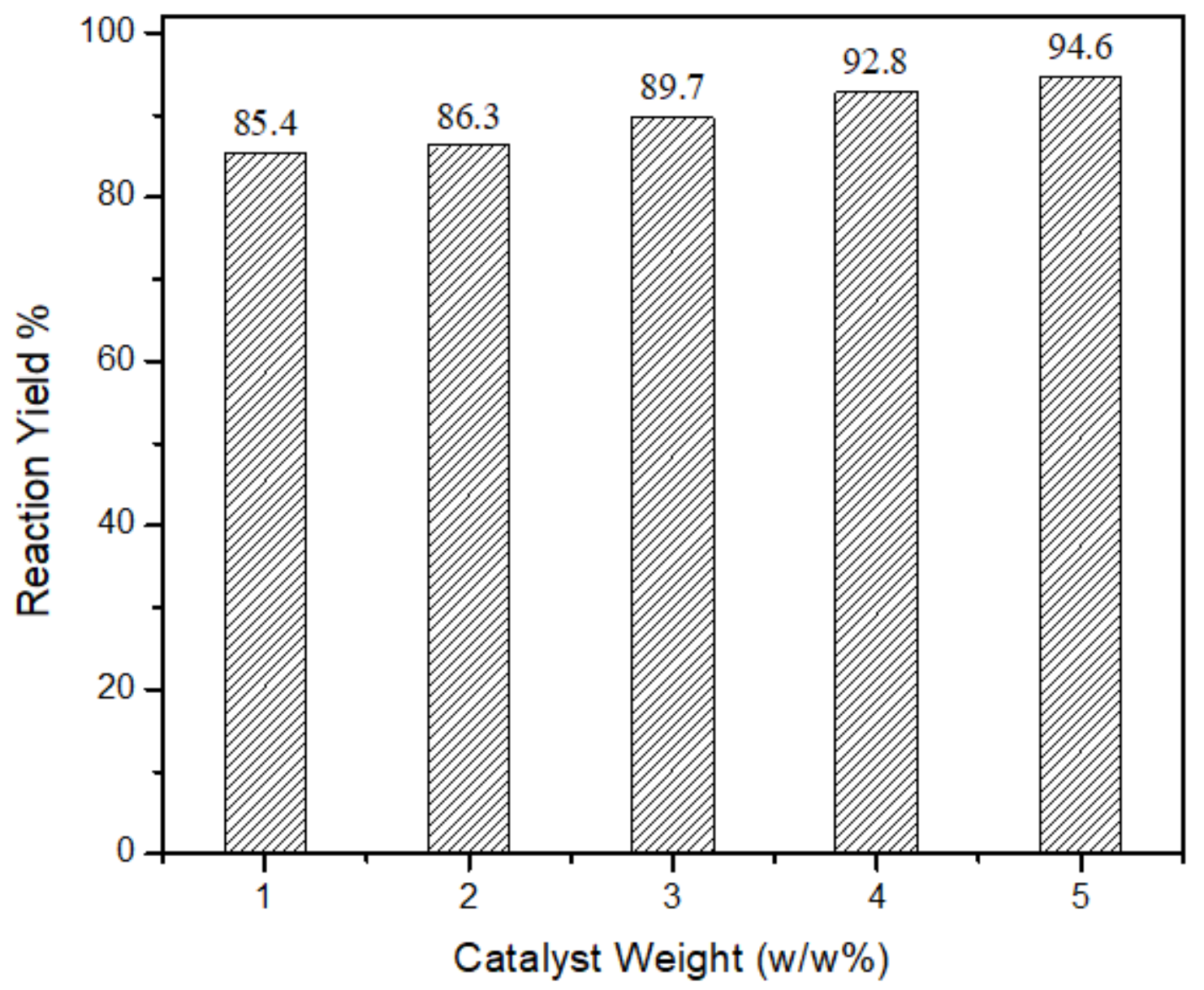

Figure 12

Influence of catalyst weight on biodiesel production using $\mathrm{KOH}$ catalyst 


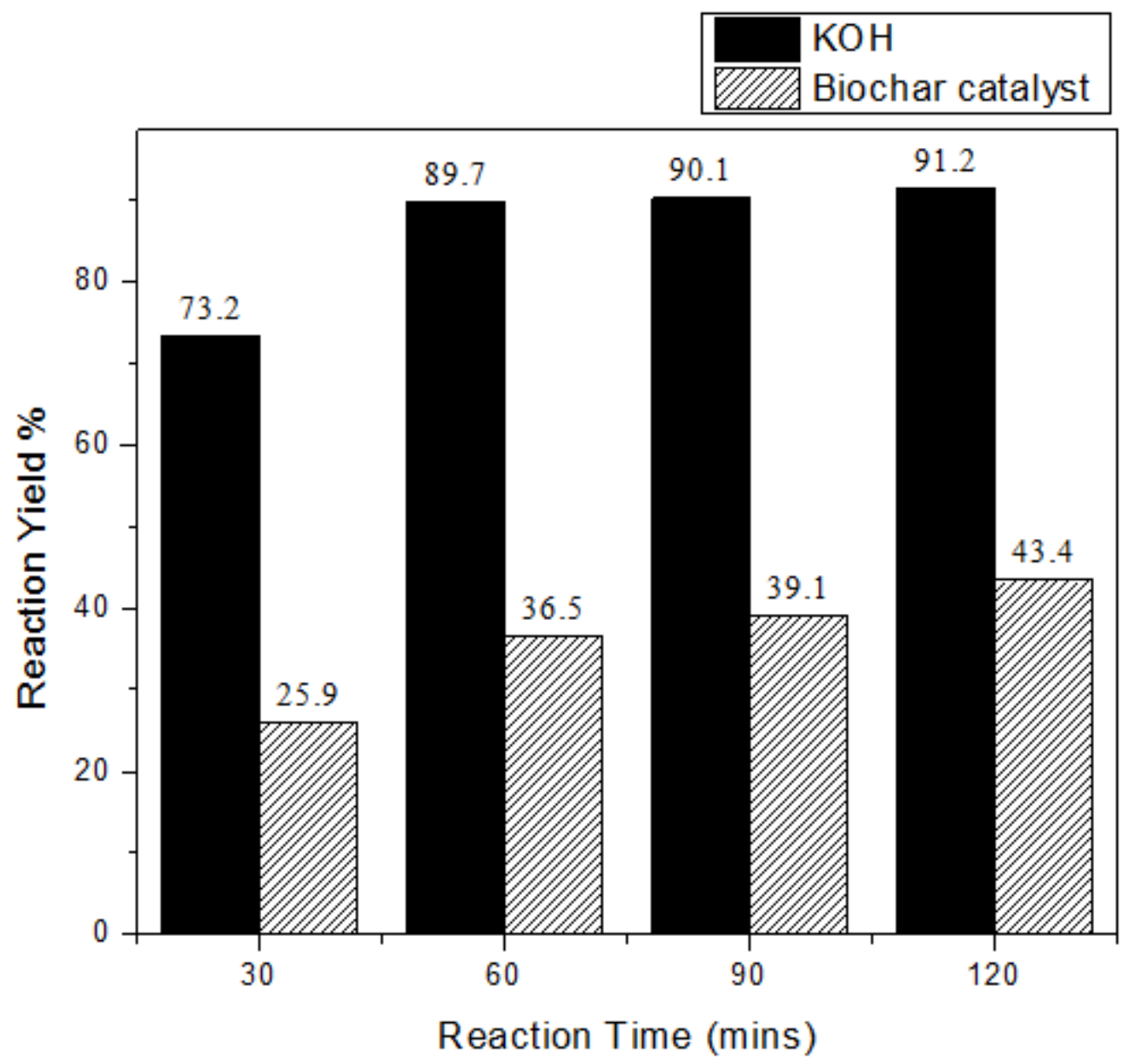

Figure 13

Comparison of Biodiesel yield using $\mathrm{KOH}$ and Biochar Catalyst 